\title{
Corrosion Inhibition on Mild Steel in Sulphuric Acid Medium Using Natural Product as Inhibitor
}

\author{
P. MATHESWARAN ${ }^{1}$, P. AMUDHA ${ }^{2 *}$, B. ANAND ${ }^{3}$ and V. BALASUBRAMANIAN ${ }^{4}$
}

${ }^{1}$ Department of Chemistry, Vidya Vikkas College of Engineering and Technology, Namakkal, India

${ }^{2 *}$ KGGHSS, Pallipalayam, Tiruchengode, Namakkal Dt, India

${ }^{3}$ Center for Applied Research, Department of Chemistry, Mahendra Engineering College, Namakkal, India

${ }^{4}$ Department of Chemistry, AMET University, Chennai, India

pmatheswaran@gmail.com

Received 1 October 2014 / Accepted 17 October 2014

\begin{abstract}
The efficiency of L. Acidissima inhibitor on the corrosion of mild steel in acidic medium of different concentration of sulphuric acid has been investigated using weight loss measurements and FT-IR spectroscopic techniques. From the analysis it reveals that the inhibitor perform well in prevention of mild steel in $1 \mathrm{M} \mathrm{H}_{2} \mathrm{SO}_{4}$ and $2 \mathrm{M} \mathrm{H}_{2} \mathrm{SO}_{4}$ acid medium solution at room temperature in two hours. When comparing the efficiency, the inhibitor shows high efficiency in $1 \mathrm{M} \mathrm{H}_{2} \mathrm{SO}_{4}$ than $2 \mathrm{M} \mathrm{H}_{2} \mathrm{SO}_{4}$. Further the inhibition efficiency also been confirmed by surface morphological studies.
\end{abstract}

Keywords: Mild steel plate, Natural inhibitors, Eco friendly, Weight loss method, Surface Analysis

\section{Introduction}

In industrial applications mild steel were widely used which is intensified by various researchers in corrosion resistance in various aggressive environments ${ }^{1-3}$. Several researchers devoted their attention to develop more effective and non-toxic inhibitors to reduce the acid attack and protection aspects ${ }^{4-9}$ were the problems arise from many industries. Amongst the various methods available, the use of inhibitors is one of the most practical methods for protection against corrosion especially in acidic media ${ }^{10-15}$. Natural products like lignin and tannin ${ }^{16}$, cinchona alkaloids ${ }^{17}$ and pomegranate alkaloids ${ }^{18}$ have been evaluated as very effective acid corrosion inhibitors in standard as well as in stringent conditions. Inhibition of corrosion was studied with the extracts of Antrographis paniculata $^{19}$, Adathoda Vasica and Piper Nigrum. L $^{20}$ and with Allamanda Balanchetti ${ }^{21}$. The natural inhibitors studied have been found to be highly ecofriendly and possess no threat to the environment. In the present work, a systematic study has been undertaken to understand the corrosion behaviour of mild steel and the inhibitive action of L. Acidissima extract on 
$1 \mathrm{M} \mathrm{H}_{2} \mathrm{SO}_{4}$ and $2 \mathrm{M} \mathrm{H}_{2} \mathrm{SO}_{4}$ environment. It was found that the absorbed inhibitor on the mild steel surface accounts for protecting the metal from the corrosive medium and modifying the electrode reactions which is in favour of corrosion protection of the metal.

\section{Experimental}

The mild steel material of composition $\mathrm{C}=0.012 \%$; $\mathrm{Si}=0.010 \%$; $\mathrm{Mn}=0.19 \% 5 ; \mathrm{S}=0.014 \%$; $\mathrm{P}=0.009 \%$; $\mathrm{Ni}=0.014 \% ; \mathrm{Mo}=0.013 \%$; $\mathrm{Cr}=0.040 \%$ and $\mathrm{Fe}=99.693 \%$ were cut into pieces of $5 \times 1 \mathrm{~cm}$ strips for this study. They were polished according to the ASTM procedure ${ }^{22}$ using emery sheet of different grids, a hole at one end and numbered were punched over the surface of mild steel plate. The metal was polished with different grades of SiC abrasive papers (from grits 120 to 1200) and it is degreased using acetone.

\section{Preparation of solutions}

\section{Preparation of extracts}

The fruit of L. acidissima were cut into small pieces, shade dried and powdered. An aqueous extract of L. acidissima were prepared with soxhlet apparatus. From this various milli molar concentration of inhibitor solutions has been prepared. All the solutions were prepared using NICE brand AR grade chemicals in double distilled water and bubbling purified by nitrogen gas for 30 minutes to carry out de-aeration of the electrolytes. $1 \mathrm{M} \mathrm{H}_{2} \mathrm{SO}_{4}$ and $2 \mathrm{M} \mathrm{H}_{2} \mathrm{SO}_{4}$ solution was prepared by double distilled water.

\section{Weight loss measurement}

Mild steel specimens were immersed in $1 \mathrm{M} \mathrm{H}_{2} \mathrm{SO}_{4}$ and $2 \mathrm{M} \mathrm{H}_{2} \mathrm{SO}_{4}$ for two hours at room temperature $\left(28 \pm 2{ }^{\circ} \mathrm{C}\right)$ at various concentration of inhibitor solution. After the duration of two hours the test specimens were removed rinsed in distilled water which is doubly purified and with acetone solution. The weight loss of the specimen were determined and recorded. From this, the inhibiton efficiency (IE \%) was calculated using the following formula,

$$
I E \%=\frac{W_{o}-W_{i}}{W_{o}} \times 100
$$

Where, $\mathrm{W}_{\mathrm{O}}$ and $\mathrm{W}_{\mathrm{i}}$ (in g) are the values of the weight loss observed of mild steel in the absence and presence of inhibitor respectively.

\section{Scanning electron microscope (SEM analysis)}

Using Scanning Electron Microscope (SEM- HITACHI S3000H, Japan) the surface of the metal was examined which is immersed into blank and inhibitor solution for two hours.

\section{FT-IR studies}

After the weight loss measurement the corroded parts were scrapped and the product was used for FT-IR studies. Using this spectral study the nature of adsorption of the inhibitor molecule over the metal surface was analyzed using FT-IR spectrophotometer (Perkin Elmer-1400).

\section{Results and Discussion}

\section{Weight loss method}

The comparison graph of corrosion behaviour and inhibitor efficiency of mild steel in $1 \mathrm{M}$ $\mathrm{H}_{2} \mathrm{SO}_{4}$ and $2 \mathrm{M} \mathrm{H}_{2} \mathrm{SO}_{4}$ with L. acidissima was shown in Figure 1(a). Inhibition Efficiency 
of L. acidissima was given in Figure 1 (b) which was studied by weight loss method at $2 \mathrm{~h}$ at room temperatures. From the graph, it was experientially verified that the weight loss of mild steel in the acid decreases with increasing concentration of additives and the values were tabulated in Table 1 from which it clearly states that the corrosion rate has decreased with increasing concentration of inhibitor and inhibition efficiency increased with increasing the concentration of the inhibitor ${ }^{9}$. The inhibition efficiency in $1 \mathrm{M} \mathrm{H}_{2} \mathrm{SO}_{4} 54.89 \%$ and in $2 \mathrm{M} \mathrm{H}_{2} \mathrm{SO}_{4}$ the efficiency was $50.36 \%$ respectively at optimum concentration of the inhibitor solution for two hours at room temperature.

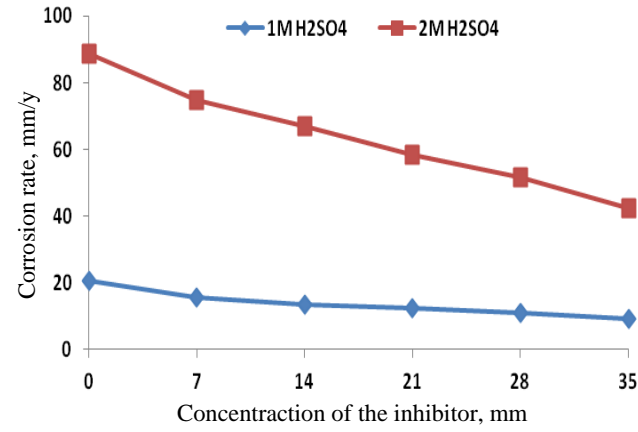

Figure 1(a). Comparision study of corrosion behaviour on $1 \mathrm{M} \mathrm{H}_{2} \mathrm{SO}_{4}$ and $2 \mathrm{M} \mathrm{H}_{2} \mathrm{SO}_{4}$ in L. acidissima

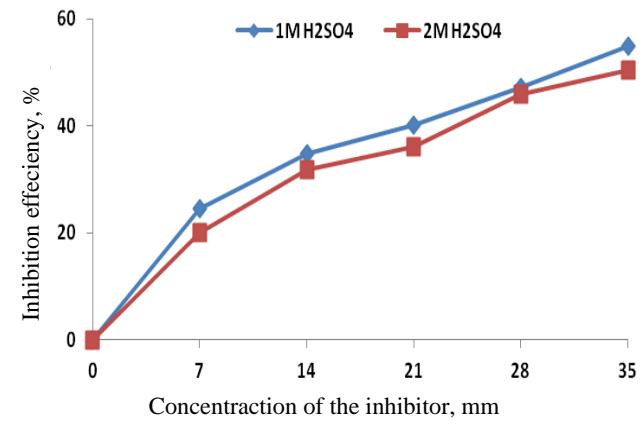

Figure 1(b). Comparision study of Inhibiton Effciency on $1 \mathrm{M} \mathrm{H}_{2} \mathrm{SO}_{4}$ and $2 \mathrm{M} \mathrm{H}_{2} \mathrm{SO}_{4}$ in L. acidissima

Table 1. Corrosion parameters in absence and presence of L. acidissima $1 \mathrm{M} \mathrm{H}_{2} \mathrm{SO}_{4}$ and $2 \mathrm{M} \mathrm{H}_{2} \mathrm{SO}_{4}$

\begin{tabular}{lccccc}
\hline \multirow{2}{*}{$\begin{array}{c}\text { Inhibitor } \\
\text { Conc. of } \\
\text { inhibitor } \\
\mathrm{mM}\end{array}$} & $\begin{array}{c}\text { Corrosion } \\
\text { Rate, } \mathrm{mm} / \mathrm{y}\end{array}$ & $\begin{array}{c}\text { Inhibitor } \\
\text { Efficiency, \% }\end{array}$ & $\begin{array}{c}\text { Corrosion } \\
\text { Rate, mm/y }\end{array}$ & $\begin{array}{c}\text { Inhibitor } \\
\text { Efficiency, } \\
\%\end{array}$ \\
\cline { 2 - 6 } & \multicolumn{2}{c}{$1 \mathrm{M} \mathrm{H}_{2} \mathrm{SO}_{4}$} & \multicolumn{2}{c}{$2 \mathrm{M} \mathrm{H}_{2} \mathrm{SO}_{4}$} \\
\hline \multirow{4}{*}{ L. acidissima } & Blank & 20.5068 & --- & 88.8259 & -- \\
& 7.00 & 15.4916 & 24.45 & 74.6717 & 20.09 \\
& 14.01 & 13.3740 & 34.78 & 67.0931 & 31.71 \\
& 21.02 & 12.2595 & 40.21 & 58.5114 & 36.07 \\
& 28.03 & 10.8106 & 47.28 & 51.7129 & 46.00 \\
& 35.04 & 9.2503 & 54.89 & 42.4625 & 50.36 \\
\hline
\end{tabular}

From the result obtained it was also concluded that the inhibitor was very efficient for preventing mild steel corrosion in $1 \mathrm{M} \mathrm{H}_{2} \mathrm{SO}_{4}$ and $2 \mathrm{M} \mathrm{H}_{2} \mathrm{SO}_{4}$. While comparing the result the inhibitor efficiency of $1 \mathrm{M} \mathrm{H}_{2} \mathrm{SO}_{4}$ is higher than $2 \mathrm{M} \mathrm{H}_{2} \mathrm{SO}_{4}$. Figure 2(a) revealed the comparison of corrosion rate (CR) with the inhibitor (in \%) in $1 \mathrm{M} \mathrm{H}_{2} \mathrm{SO}_{4}$ and $2 \mathrm{M} \mathrm{H}_{2} \mathrm{SO}_{4}$ solution at $2 \mathrm{~h}$ at room temperature. Comparison of inhibition efficiency (IE) with concentration of L. acidissima (in \%) in $1 \mathrm{M} \mathrm{H}_{2} \mathrm{SO}_{4}$ solution for two hours at room temperature is shown in Figure 2(b).

\section{FT-IR spectral studies}

This study is very useful in predicting the type of adsorption as well as bonding formation takes place at optimum concentration between the metal surface and the inhibitor used. Figure 2(a) represents the IR spectrum peaks of the inhibitor. In this spectrum the peak appeared at $3367 \mathrm{~cm}^{-1}$ corresponds to amide N-H stretching, $1510 \mathrm{~cm}^{-1}$ corresponds to $\mathrm{C}=0$ 
group, $1417 \mathrm{~cm}^{-1}$ corresponds to C-C stretching and from $1230 \mathrm{~cm}^{-1}$ to $1000 \mathrm{~cm}^{-1}$ the wavenumber indicates the presence of $\mathrm{C}-\mathrm{O}$ bonding nature. Figure 2 (b and c) is similar to Figure 2 (a) which indicates the corrosion products contains L. acidissima in $1 \mathrm{M} \mathrm{H}_{2} \mathrm{SO}_{4}$ and $2 \mathrm{M} \mathrm{H}_{2} \mathrm{SO}_{4}$. Therefore from the spectral data it is concluded that physisorption takes place between metal surface and the inhibitor molecule.

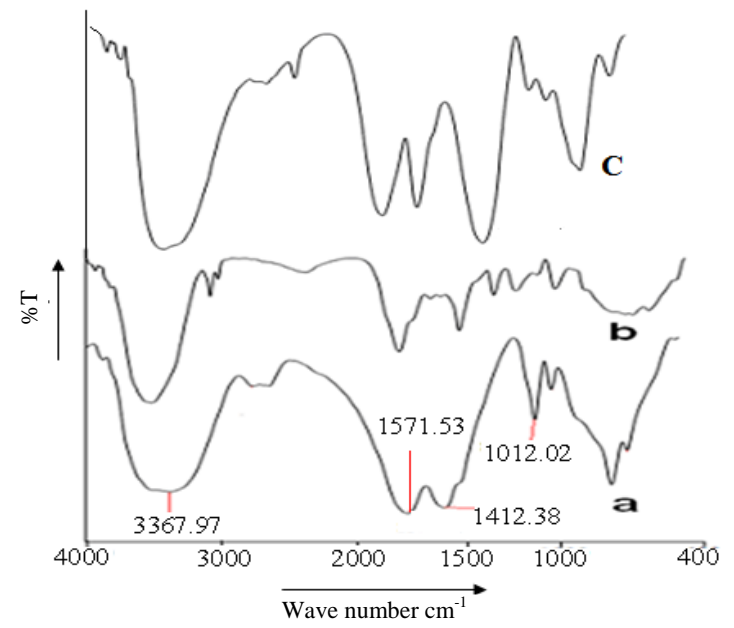

Figure 2. IR spectrum of the corrosion product showing adsorption in the presence of aqueous extract of L. acidissima

\section{SEM analysis}

The mild steel material which is cut into pieces were polished and immersed in the test solution for two hours acid solution. The test sample was prepared using double distilled water. The specimens were dipped into $1 \mathrm{M} \mathrm{H}_{2} \mathrm{SO}_{4}$ and $2 \mathrm{M} \mathrm{H}_{2} \mathrm{SO}_{4}$ which contains the inhibitor L. acidissima at optimum concentration and then the specimens were removed from the beaker, dried and kept in desiccators and it was observed under Scanning Electron Microscope (SEM) for surface morphological studies. The micrograph is shown in the Figure 3-6 show that the polished specimen was immersed in the blank solution of $1 \mathrm{M}$ $\mathrm{H}_{2} \mathrm{SO}_{4}$ and $2 \mathrm{M} \mathrm{H}_{2} \mathrm{SO}_{4}$ and in the acids containing inhibitor L. acidissima which associated with polishing scratches. This result improves the surface coverage of the metal so that there is a decrease in the contact between metal and the aggressive medium.

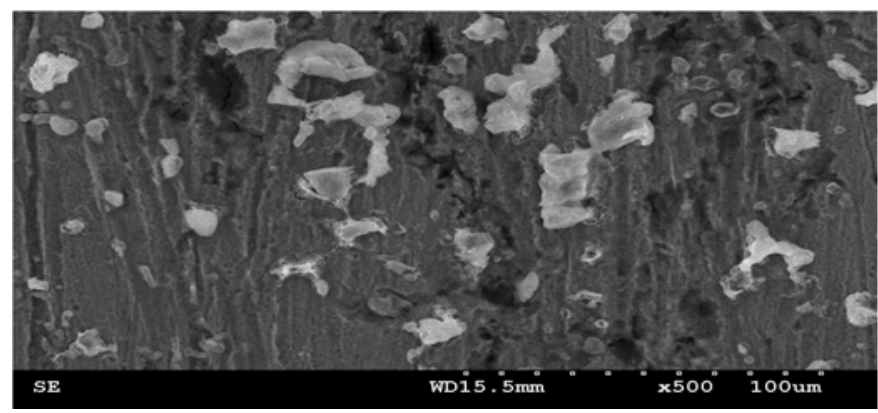

Figure 3. SEM images obtained for the mild steel surfaces immersed for $2 \mathrm{~h}$ in $1 \mathrm{M}$ $\mathrm{H}_{2} \mathrm{SO}_{4}$ (blank acid solution) 


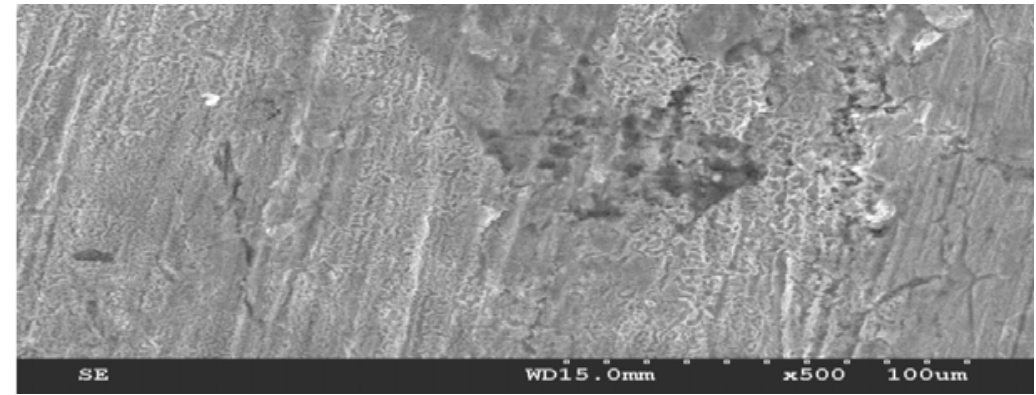

Figure 4. SEM images obtained for the mild steel surfaces immersed for $2 \mathrm{~h}$ in $1 \mathrm{M} \mathrm{H}_{2} \mathrm{SO}_{4}$ with $35.04 \mathrm{mM}$ inhibitor solution

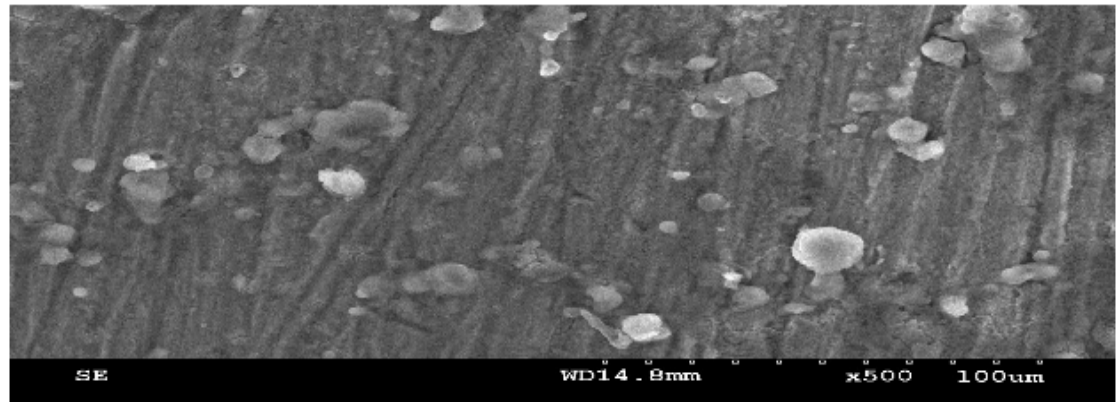

Figure 5. SEM images obtained for the mild steel surfaces immersed for $2 \mathrm{~h}$ in $2 \mathrm{M} \mathrm{H}_{2} \mathrm{SO}_{4}$ (blank acid solution)

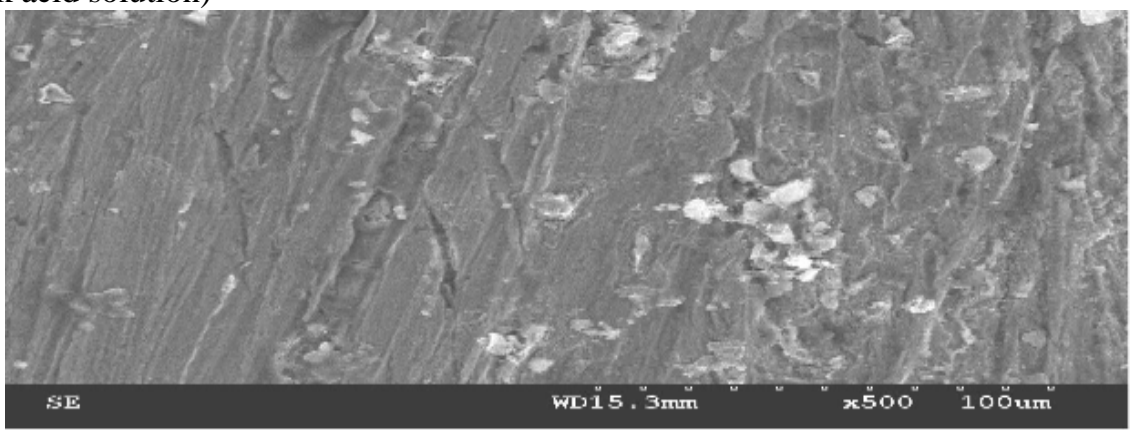

Figure 6. SEM images obtained for the mild steel surfaces immersed for $2 \mathrm{~h}$ in $2 \mathrm{M} \mathrm{H}_{2} \mathrm{SO}_{4}$ with $35.04 \mathrm{mM}$ inhibitor solution.

\section{Conclusion}

From this above investigation it was concluded that the

1. L. acidissima shows better inhibiton efficiency when dipped in $1 \mathrm{M} \mathrm{H}_{2} \mathrm{SO}_{4}$ and $2 \mathrm{M}$ $\mathrm{H}_{2} \mathrm{SO}_{4}$. On comparing $1 \mathrm{M} \mathrm{H}_{2} \mathrm{SO}_{4}$ shows better results than $2 \mathrm{M} \mathrm{H}_{2} \mathrm{SO}_{4}$.

2. The inhibition efficiency of L. acidissima in $1 \mathrm{M} \mathrm{H}_{2} \mathrm{SO}_{4}$ was found to be $54.89 \%$ whereas in $2 \mathrm{M} \mathrm{H}_{2} \mathrm{SO}_{4}$ it shows $50.36 \%$ at optimum concentration.

3. FT-IR analysis confirm that the inhibiton efficiency of the inhibitor in mild steel through electrostatic attraction of inhibitor molecule and the metal surface.

4. The effective protection of mild steel, through the less damaged and minimum crack found in the inhibited surface confirmed from surface morphological studies. 


\section{Acknowledgement}

I very much thankful to AMET University for providing the facilities for smooth conduction of this research work.

\section{Reference}

1. $\quad$ Ning S G and Shi M L, J Chin Soc Corros Prot., 1990, 10, 383.

2. $\quad$ EI Mehdia B, Mernari B,Traisnel M, Bentiss F and Lagrenee M, Mater Chem Phys., 2002, 77(2), 489; DOI:10.1016/S0254-0584(02)00085-8

3. Govindaraju K M, Gopi D and Kavitha L, J Appl Electrochem., 2009, 39(2), 269-276; DOI:10.1007/s10800-008-9666-4

4. Zerga B, Sfaria M, Rasis Z, Ebn Touhami M, Taleb M, Hammouti B, Imelouane B and Elbachiri A, Mater Tech., 2009, 97, 297

5. Chaieb E, Bouyanzer A, Hammouti B and Benkadour M, Appl Surf Sci., 2005, 246(1-3), 199-206; DOI:10.1016/j.apsusc.2004.11.011

6. Bouklah M and Hammouti B, Port Electrochim Acta, 2006, 24(4), 457-468.

7. Bouyanzer A, Majidi L and Hammouti B, Phys Chem News., 2007, 37, 70-74.

8. Ferreira E S, Giacomelli C, Gicomelli F C and Spinelli A, Mater Chem Phys., 2004, 83(1), 129-134; DOI:10.1016/j.matchemphys.2003.09.020

9. Bouklah M, Ouassini A, Hammouti B and EI Idrissi A, Appl Surf Sci., 2006, 252(6), 2178-2185; DOI:10.1016/j.apsusc.2005.03.177

10. Anand B, Jayndran M and Balasubramainan V, Asian J Chem., 2011, 23(5), 2106-2108.

11. Anand B and Balasubramainan V, Int J Adv Mater Sci., 2011, 1(1), 1-7.

12. Matheswaran. P and Ramasamy A K, J Chem., 2010, 7(4), 1284-1289; DOI:10.1155/2010/546360

13. Gopi D, Manimozhi S, Govindaraju K M, Manisankar P and Rajeswari S, J Appl Electrochem., 2007, 37, 439-449; DOI:10.1007/s10800-006-9274-0

14. Aloui S, Forsal I, Sfaira M, Ebn Touhami M, Taleb M, Filali Baba M and Daoudi M, Portugaliae Electrochim Acta., 2009, 27, 599.

15. Kustu C, Emregul KC and Atakol O, Corros Sci., 2007, 49(7). 2800-2814; DOI:10.1016/j.corsci.2007.02.002

16. Zhang Q B and Hua Y X, Electrochim Acta., 2009, 54(6), 1881-1887; DOI:10.1016/j.electacta.2008.10.025

17. Abiola O K, Oforka N C and Ebenso E E, Bull Electro Chem., 2004, 20(9), 409.

18. Moretti G and Guidi F, Corros Sci., 2002, 44(9), 1995-2011; DOI:10.1016/S0010938X(02)00020-3

19. Bentiss F, Lebrini M and Lagrene M, Corros Sci., 2005, 47(12), 2915-2931; DOI:10.1016/j.corsci.2005.05.034

20. Matheswaran P and Ramasamy A K, J Chem., 7(3), 1090-1094; DOI:10.1155/2010/598025

21. Anand B and Balasubramanian V, E-J Chem., 2011, 8(1), 226-230; DOI:10.1155/2011/345095

22. Matheswaran P and Ramasamy A K, Asian J Chem., 2011, 23(10), 4447-4450. 